\title{
Geleitwort der Herausgeberin
}

Die Kanzlei Peters, Schönberger \& Partner (PSP), München, ist seit ihrer Gründung vor über 40 Jahren dem Stiftungswesen eng verbunden. Als multidisziplinäre Kanzlei von Rechtsanwälten, Steuerberatern und Wirtschaftsprüfern beraten wir nicht nur Stiftungserrichtungen, sondern unterstützen viele Stiftungen laufend in rechtlichen und steuerlichen Angelegenheiten, als Abschlussprüfer sowie mit unserem Family Office in Fragen der Vermögensbewirtschaftung.

Viele Partner der Kanzlei sind in Gremien von Stiftungen tätig und kennen deren Problemstellungen und Beratungsbedarf daher aus der Praxis. Darüber hinaus ist PSP selbst Stifter der Stiftung Recht \& Gesellschaft, die u.a. jährlich den „Münchner Gemeinnützigkeitstag" veranstaltet.

Anfang des Jahres 2020 fiel der Entschluss, das Gesetzgebungsverfahren zur Stiftungsrechtsreform mit einem Leitfaden für die Stiftungspraxis zu begleiten. Dieses Buch ist aus der von PSP herausgegebenen Online-Ausgabe dieses Leitfadens „Die Stiftungsrechtsreform“ hervorgegangen, die erstmals im Mai 2020 erschienen und danach mehrfach aktualisiert worden ist. PSP übernahm auch die Herausgabe des vorliegenden Buchs und wird unter www.psp.eu/npo über die weiteren rechtlichen Entwicklungen laufend informieren.

München, im Oktober 2021

Die Herausgeberin 
